\title{
Cloning of nucleoplasmin from Xenopus laevis oocytes and analysis of its developmental expression
}

\author{
Thomas R. Bürglin, Iain W. Mattaj, Donald D. Newmeyer, Rolf Zeller, and Eddy M. De Robertis
}

Biocenter of the University of Basel, $\mathrm{CH} 4056$ Basel, Switzerland, and Department of Biological Chemistry, University of California at Los Angeles, California 90024 USA

\begin{abstract}
Nucleoplasmin is the most abundant protein in the nucleus of Xenopus laevis oocytes. We cloned a cDNA coding for nucleoplasmin from an expression library of immature Xenopus laevis oocytes. The deduced amino acid sequence shows that the carboxyl terminus is very hydrophilic and contains an unusual stretch of 12 glutamic acid residues, which is consistent with one of the proposed functions of nucleoplasmin - that of promoting chromatin assembly. The last $\mathbf{5 0}$ amino acids are lysine- and alanine-rich and contain short stretches of homology to histone H1. These regions could be involved in interactions with nucleosomes. The levels of nucleoplasmin mRNA and protein during oogenesis and embryogenesis were investigated using Northern blots, Western blots, and in situ hybridization to oocyte sections. The mRNA is detected during oogenesis but not during embryogenesis, suggesting that nucleoplasmin may be an exclusively maternally expressed gene.

However, the protein is present throughout embryogenesis and undergoes pronounced changes in its level of phosphorylation during maturation of the oocyte and just after midblastula transition. These results support the notion that nucleoplasmin is not only important in oocytes but also plays a major role during the rapid cleavages of early embryogenesis.
\end{abstract}

[Key Words: Nuclear protein; expression library; in situ hybridization; oogenesis; embryogenesis]

Received November 17, 1986; accepted December 8, 1986.

Nucleoplasmin is the most abundant protein in the nucleus of Xenopus laevis oocytes (Krohne and Franke 1980a; Mills et al. 1980). It is a protein with a molecular mass of about $30 \mathrm{kD}$ and forms a stable pentamer in vivo (Earnshaw et al. 1980). It is acidic and highly phosphorylated, and its thermostability provides the basis for an easy purification method (Laskey et al. 1978; Earnshaw et al. 1980; Cotten et al. 1986). In ooctyes, the pentamer is complexed with histones (Kleinschmidt et al. 1985),

1Present address: Department of Biological Chemistry, University of California, Los Angeles, California 90024 USA.

${ }^{2}$ Present address: European Molecular Biology Laboratory, 6900 Heidelberg 1, Federal Republic of Germany.

${ }^{3}$ Present address: Department of Biology, University of California at San Diego, La Jolla, California 92093 USA.

${ }^{4}$ Present address: Department of Genetics, Harvard Medical School, Boston, Massachusetts 02115 USA. and it has been found to assemble histones into nucleosomes in the presence of DNA in vitro (Laskey et al. 1978; Earnshaw et al. 1980; Sealy et al. 1986). Studies with polyclonal antibodies indicate that nucleoplasmin is present not only in oocytes and embryos, but also in a variety of somatic tissues and in other species (Krohne and Franke 1980a,b).

This protein has received much attention because of its ability to accumulate in the oocyte nucleus after microinjection into the cytoplasm (Mills et al. 1980), and it is now one of the best studied nuclear-migrating proteins in higher eukaryotes. It was the first protein for which a signal for nuclear transport was localized to a specific domain (Dingwall et al. 1982). The protein was proteolytically cleaved into a "core" and a "tail" fragment, and only the "tail" fragment was able to target to the nucleus. Feldherr et al. (1984) demonstrated that transport of nucleoplasmin occurs through the nuclear 
pore using gold particles coated with nucleoplasmin. Newmeyer et al. (1986) showed that ATP is required for its transport into nuclei in oocytes and in egg extracts in vitro. The fate of this protein during maturation and embryogenesis has been studied by Dreyer and Hausen (1983) and Hausen et al. (1985) using monoclonal antibodies. They found that it distributes through the cytoplasm in the animal half of the egg during breakdown of the oocyte nucleus, migrates back into nuclei during early cleavage, and can be seen in nuclei up to the swimming tadpole stage.

To understand further the expression and function of nucleoplasmin, we have cloned a cDNA coding for the protein from an expression library made from ovary RNA of immature Xenopus laevis. Using this cDNA probe and an anti-nucleoplasmin serum, we have analyzed the pattern of nucleoplasmin expression, during oogenesis and embryogenesis. Our results suggest that nucleoplasmin, although transcribed only during oogenesis, plays an important role during early embryogenesis. Furthermore, the deduced amino acid sequence revealed a striking stretch of glutamic acid residues, which is consistent with its proposed function in chromatin assembly.

\section{Results}

Raising of an antiserum against nucleoplasmin and isolation of a cDNA clone

An antiserum against purified nucleoplasmin was raised in rabbits. Paraffin sections of oocytes were incubated with the antiserum and the bound antibodies were visualized with Protein A-gold complexes, followed by enhancement with a photochemical silver method. Figure 1 shows that the immunolocalization is nuclear as expected. The antiserum also reacts with a protein band of the correct molecular weight in oocyte extracts that were separated by SDS gel electrophoresis and subse-

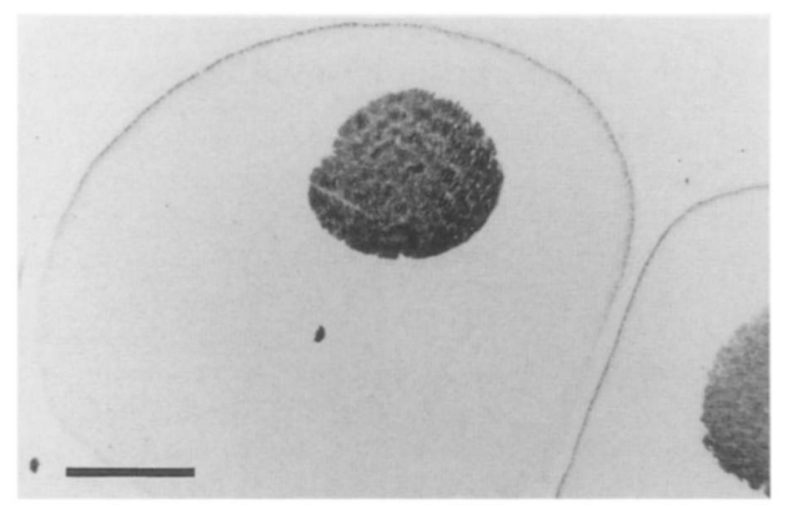

Figure 1. Immunolocalization of nucleoplasmin in the nucleus of $X$. laevis oocytes. Paraffin sections of stage 5 oocytes (Dumont 1972) were incubated with anti-nucleoplasmin serum and the antibodies were detected with Protein A-gold complexes. The gold staining was then enhanced using a photochemical silver method. Bar, $200 \mu \mathrm{m}$. quently transferred to nitrocellulose (Western blots; Towbin et al. 1979), as can be seen in Figure 8b (below). Sera from some of the later boosts showed cross-reactivity with other Xenopus proteins (see Fig. 7b, below).

cDNA was prepared from poly $(\mathrm{A})^{+}$RNA obtained from ovaries of recently metamorphosed frogs (stage 65, Nieuwkoop and Faber 1967). This cDNA was cloned into the $\lambda$ gt1l expression vector (Young and Davis 1983); a library with about 50,000 independent recombinant phages was screened with anti-nucleoplasmin serum and two positive clones were isolated. To confirm that the clones were reacting with nucleoplasmin antibodies and not with other contaminating antibodies in the serum, the fusion proteins obtained from the $\lambda g t 11$ recombinants were used to affinity-purify antibodies using a modification of the method of Olmsted (1981). Bacterial lysates containing the fusion proteins produced by the positive phages were separated on preparative SDS-polyacrylamide gels and transferred to nitrocellulose. Thin strips were cut from the region of the fusion proteins. The strips were then incubated with anti-nucleoplasmin serum and, after washing, the bound antibodies were eluted at low $\mathrm{pH}$. Only one clone yielded affinity-purified antibodies that reacted with nucleoplasmin on a Western blot of Xenopus oocyte extract (Fig. 2, lane i). Sequencing later confirmed that the other clone did not code for nucleoplasmin.

Figure 2 (lane d) shows the fusion protein produced by the nucleoplasmin clone N7.2 after electrophoresis in a SDS gel. The fusion protein has a molecular mass of about $150 \mathrm{kD}$ and is thus about $35 \mathrm{kD}$ larger than $\beta$-galactosidase (Fig. 2, lane c). The crude anti-nucleoplasmin serum reacts with the fusion protein (Fig. 2, lane g), but also cross-reacts with many Escherichia coli proteins. However, after affinity purification against the fusion protein, the eluted antibodies react only with the fusion protein (Fig. 2, lane h) on strips of Western blots of bacterial lysates. Similarly, the affinity-purified antibodies react almost exclusively with a protein band of the appropriate molecular weight for nucleoplasmin on strips of Western blots of Xenopus oocyte extracts, while the other cross-reacting bands seen with the crude serum are barely detectable (Fig. 2, compare lane i with lane i).

These results strongly suggest that the clone indeed codes for at least part of nucleoplasmin, since it is very unlikely that a polyclonal serum that had been affinitypurified against the fusion protein would cross-react with another Xenopus protein of the correct molecular weight.

\section{Sequencing and open reading frame determination}

Final proof that the cDNA indeed corresponds to nucleoplasmin came from DNA sequencing. Figure 3 shows the sequence of the clone N7.2, which is $654 \mathrm{bp}$ long. Sequence analysis by computer reveals only one long open reading frame of 192 amino acids, which is in frame with the carboxyl terminus of $\beta$-galactosidase. The open reading frame codes for the carboxy-terminal $21 \mathrm{kD}$ of nucleoplasmin. Table 1 (panel B) shows the comparison of the deduced amino acid composition of 


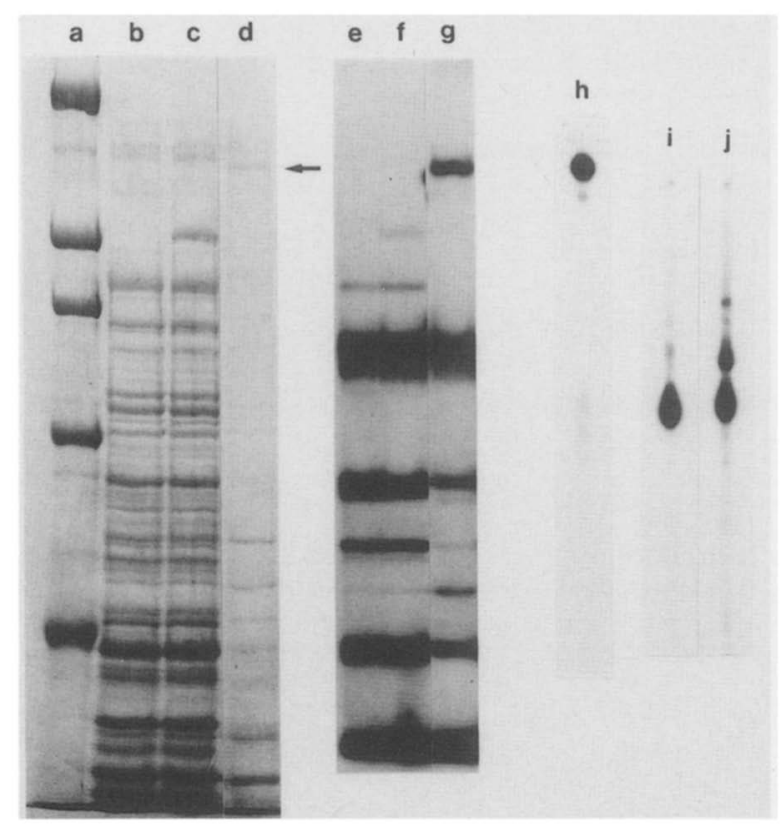

Figure 2. Characterization of the clone using affinity-purified antibodies. Fusion proteins from $\lambda$ gt 11 and clone N7.2 were expressed in E. coli Y1089. The cells were sonicated and the protein extracts were separated on $7.5 \%$ SDS-polyacrylamide gels. Gels were then either stained with Coomassie Blue (lanes $a-d$ ) or transferred to nitrocellulose and stained with anti-nucleoplasmin serum (lanes $e-g$ ) or stained with affinity-purified antibodies against the fusion protein (lane $h$ ). Xenopus oocyte extracts were separated on $15 \%$ SDS-polyacrylamide gels, transferred to nitrocellulose, and stained with affinity-purified antibody (lane i) or crude anti-nucleoplasmin serum (lane $i$. (Lane a) Protein molecular weight markers-first three markers from the top are: myosin, $200 \mathrm{kD}$; $\beta$-galactosidase, 116 $\mathrm{kD}$; phosphorylase $\mathrm{B}, 92.5 \mathrm{kD}$. (Lane $b$ ) Crude $\lambda$ gt 11 protein extract from a culture not induced with IPTG. (Lane $c$ ) Same as lane $b$, but induced with IPTG. (Lane $d$ ) Crude protein extract of the N7.2 clone from a culture induced with IPTG. The extract was precipitated with $35 \%$ ammonium sulfate prior to gel separation. Note the difference in size of the fusion protein (arrow) compared with $\beta$-galactosidase. (Lanes $e-g$ ) Same samples as lanes $b, c$, and $d$, respectively, after transfer to nitrocellulose and staining with anti-nucleoplasmin serum. Note the staining of the fusion protein. (Lane $h$ ) Same as lane $g$, but stained with anti-nucleoplasmin serum which had been affinity-purified against N7.2 fusion (see text and Materials and methods). Only the fusion protein stains now. (Lane i) Same affinity-purified antibody as in lane $h$ stains only nucleoplasmin on Xenopus oocyte extracts. (Lane i) Crude anti-nucleoplasmin serum shows some other cross-reacting bands on Xenopus oocyte extracts.

this clone with the published amino acid composition (Earnshaw et al. 1980). Comparing the 190 amino acids of the cDNA clone to the amino acid composition of complete nucleoplasmin protein shows a similar composition.

To compare the amino acid composition of the proteolytic tail fragment published by Dingwall and Allan (1984) to the cDNA clone, the last 101 amino acids were chosen provisionally as the tail fragment, based on an optimal amino acid comparison, an appropriate molec- ular weight, and a cleavage site that conforms with preferred cutting sites for pepsin (Tang 1963). Table 1 (panel A) shows a very similar amino acid composition, proving that the cDNA clone is indeed nucleoplasmin and that the tail fragment corresponds to the carboxyl terminus of the protein as proposed by Dingwall et al. (1982).

Nucleoplasmin has been found to migrate as a doublet on SDS gels (Kleinschmidt et al. 1985; Cotton et al. 1986; Fig. 7b, below), suggesting that there may be several variants. Other slightly variant $\mathrm{cDNAs}$ have been isolated independently (Dingwall et al. 1985; C. Dingwall and R.A. Laskey, pers. comm.). Thus, we suggest that the clone described in this paper should be named nucleoplasmin A.

\section{Structural features of the clone and the amino acid sequence}

The size of the complete nucleoplasmin mRNA is estimated to be around 920 nucleotides, as judged from total oocyte RNA that was electrophoretically separated on formaldehyde-agarose gels, transferred to nitrocellulose, and hybridized to the nick-translated N7.2 clone (Northern blot, see Fig. 7a, below). Close to the 3' end, the cDNA clone has a consensus AATAAA polyadenylation signal (underlined in Fig. 3). Assuming a length of 100 nucleotides for the poly(A) tail, our clone is missing perhaps 150-200 nucleotides of the $5^{\prime}$ end. Thus, only about 50 amino acids or less of nucleoplasmin may be missing. In addition, since the fusion protein migrates in SDS gels as if $35 \mathrm{kD}$ had been inserted downstream of $\beta$-galactosidase (nucleoplasmin has an apparent molecular weight of $30 \mathrm{kD}$ ), it is possible that most of the coding region is present in the cDNA clone and that nucleoplasmin migrates anomalously slowly in SDS gels. Results by C. Dingwall et al. (pers. comm.), who have isolated a longer cDNA clone for the B variant of nucleoplasmin, suggest that only six amino acids are missing from the amino terminus of our clone.

The deduced amino acid sequence shows a fairly normal composition of amino acids in the 5' part of the clone, containing some hydrophobic regions. However, the tail is very hydrophilic and charged. A stretch of 15 amino acids, of which 14 are acidic and 12 are glutamic acid residues, starts 70 amino acids upstream of the carboxyl terminus. The amino acid composition of the last 50 amino acids is similar to histones due to the abundance of lysine and alanine residues. A search of the $\mathrm{Na}$ tional Biomedical Research Foundation protein data bank showed that sea urchin gonadal histone $\mathrm{Hl}$ and rabbit histone $\mathrm{H} 1.3$ have short stretches of high homology to the lysine-rich parts of the carboxy-terminus of nucleoplasmin (Fig. 4). However, no protein showing extended homologies to nucleoplasmin was found.

Figure 5 shows a secondary structure prediction for the sequence according to Chou and Fasman (1978). No $\beta$-sheets are predicted for the tail region, only $\alpha$-helixforming regions and turn-forming regions around the glycine- and proline-rich parts (Fig. 5). The glutamic acid 


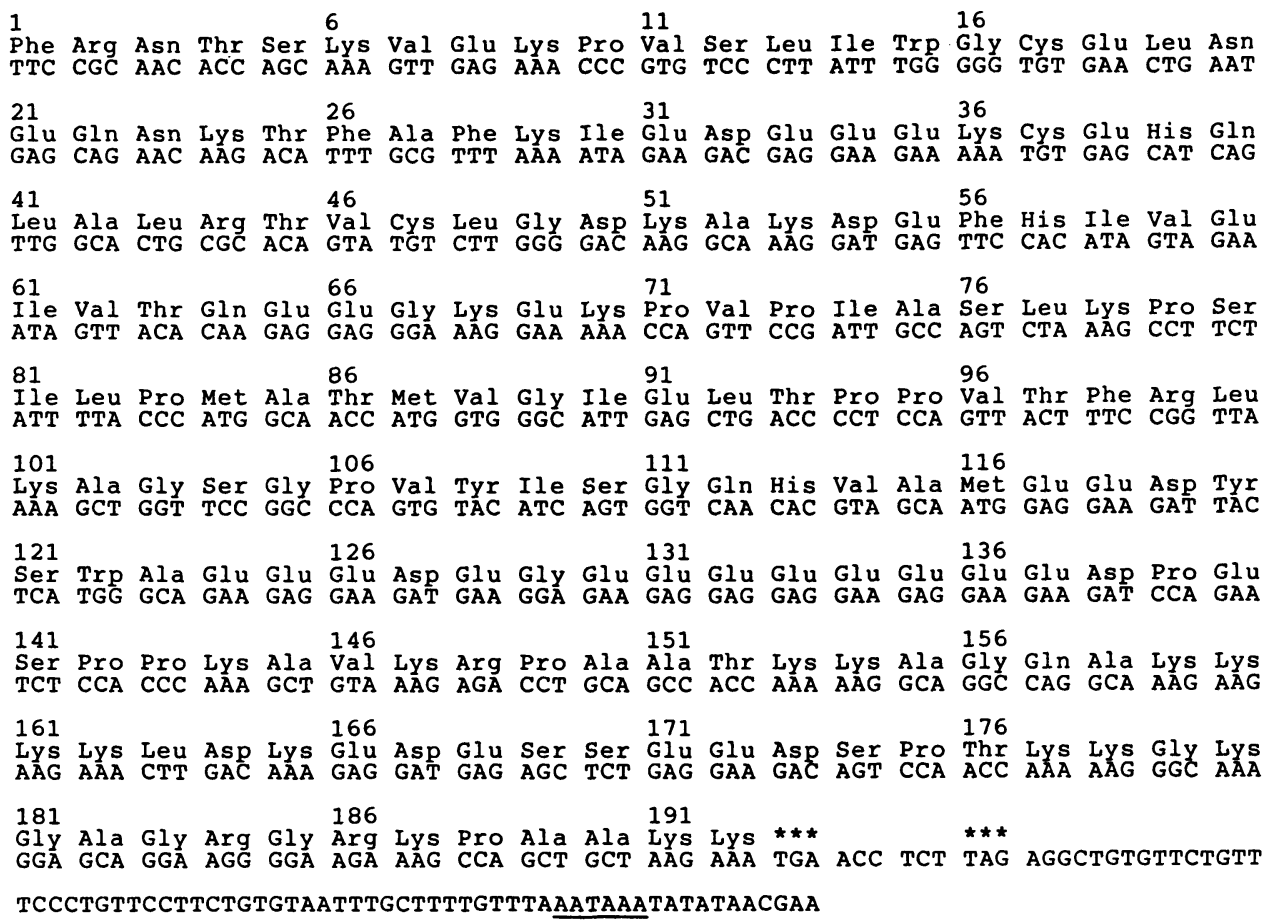

Figure 3. Sequence of nucleoplasmin A. The deduced amino acid sequence of the clone is in frame with $\beta$-galactosidase. The first two amino acids are coded by the EcoRI linker used for constructing the cDNA library. At the end of the clone a possible polyadenylation signal is found (underlined). The last four bases are EcoRI linker sequence. The numbering of the sequence is provisional, since the $5^{\prime}$ end is missing.

stretch most likely forms two $\alpha$-helixes with a turn at glycine 129. These predictions, together with the fact that the tail is very charged and hydrophilic, suggest that the tail is possibly very flexible and accessible for interaction with other proteins.

\section{Nucleoplasmin during oogenesis}

The nucleoplasmin clone was used to examine the developmental profile of nucleoplasmin expression during oogenesis and early development. Ovaries of young and adult frogs containing oocytes of different stages were embedded in paraffin and sectioned. Figure 6a shows in situ hybridization of a ${ }^{3} \mathrm{H}$-nick-translated probe to sections of immature ovaries from recently metamorphosed young frogs. This shows that nucleoplasmin mRNA is already present throughout the cytoplasm of oocytes in those early stages of oogenesis. A screen of the cDNA library with the ${ }^{32} \mathrm{P}$-nick-translated clone N7.2 yielded about 300 positive phages out of 50,000 recombinants present, indicating that nucleoplasmin is indeed an abundant message at this stage.

In situ hybridization to adult ovaries (Fig. 6b) showed that although the final destination of the protein is nuclear, the mRNA is not localized in any particular region of the cell (e.g., the perinuclear region). This is similar to the findings for histone mRNAs (Jamrich et al. 1984). Furthermore, Figure $6 \mathrm{~b}$ shows that nucleoplasmin is most concentrated in previtellogenic oocytes of stages 1 and 2 (Dumont 1972).

These results were corroborated using a different technique. Total RNA from different stages of oogenesis was
Table 1. Comparison of the amino acid compositions of nucleoplasmin and the tail fragment of the cDNA clone

\begin{tabular}{|c|c|c|c|c|}
\hline & \multicolumn{2}{|c|}{$\mathrm{A}^{\mathbf{a}}$} & \multicolumn{2}{|l|}{$\mathrm{B}^{\mathrm{b}}$} \\
\hline & $\begin{array}{l}12,000 \\
\text { m.w. } \\
\text { fragment }\end{array}$ & $\begin{array}{l}\text { last } 101 \\
\text { amino } \\
\text { acids }\end{array}$ & $\begin{array}{l}\text { total } \\
\text { nucleoplasmin }\end{array}$ & $\begin{array}{l}\text { last } 190 \\
\text { amino } \\
\text { acids }\end{array}$ \\
\hline Asn $\}$ & \multirow{2}{*}{9.1} & 0.0 & \multirow{2}{*}{9.2} & 1.6 \\
\hline Asp $\}$ & & $5.9\}$ & & 4.7 \\
\hline Thr & 4.3 & 4.0 & 5.4 & 4.7 \\
\hline Ser & 6.0 & 6.9 & 6.7 & 5.8 \\
\hline Gln $\}$ & \multirow{2}{*}{23.8} & 2.0 & \multirow{2}{*}{20.0} & 2.6 \\
\hline Glu J & & 18.8 & & 17.4 \\
\hline Pro & 8.5 & 8.9 & 7.3 & 7.4 \\
\hline Gly & 7.8 & 8.9 & 8.2 & 6.8 \\
\hline Ala & 10.3 & 10.9 & 7.2 & 8.4 \\
\hline Val & 3.4 & 4.0 & 6.2 & 5.8 \\
\hline Cys & & 0.0 & & 1.6 \\
\hline Met & 0.3 & 1.0 & 1.0 & 1.6 \\
\hline Ile & 1.4 & 1.0 & 3.2 & 4.2 \\
\hline Leu & 4.2 & 3.0 & 6.2 & 5.3 \\
\hline Tyr & 0.4 & 2.0 & 2.1 & 1.1 \\
\hline Phe & 1.2 & 1.0 & 2.3 & 2.1 \\
\hline His & 1.0 & 1.0 & 2.2 & 1.6 \\
\hline Lys & 15.6 & 15.8 & 11.3 & 13.7 \\
\hline Arg & 2.6 & 4.0 & 2.2 & 2.6 \\
\hline $\operatorname{Trp}$ & & 1.0 & trace & 1.1 \\
\hline
\end{tabular}

a Amino acid composition of the 12,000 m.w. tail fragment of nucleoplasmin compared to the last 101 amino acids of the deduced amino acid sequence from the cDNA clone.

b Amino acid composition of nucleoplasmin compared to the 190 deduced amino acids of the cDNA clone.

${ }^{c}$ Data from Dingwall and Allan (1984).

d Data from Earnshaw et al. (1980). 


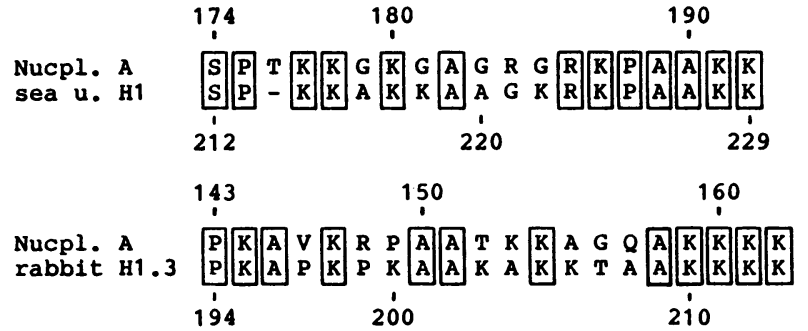

Figure 4. Homologies of the carboxyl terminus to histones. Gonadal histone $\mathrm{Hl}$ of sea urchin (Parechinus angulosus) and histone H1.3 of rabbit show short stretches of high homology to the lysine-rich parts of the carboxyl terminus of nucleoplasmin.

prepared and analyzed by Northern blots [only 2.5 oocytes equivalents of total RNA were used per lane, explaining why the bands are not crisp as in the poly(A)+ Northern of Fig. 8a]. As can be seen in Figure 7a, nucleoplasmin message is present in the early stages of oogenesis in almost the same amounts as in full-grown oocytes. The increase in nucleoplasmin mRNA from stages 1 and 2 to stage 6 is about two- to fivefold, whereas the oocytes volume increases at least 30 -fold (Zeller et al. 1983) so that the message is actually diluted in later stages, in agreement with our in situ hybridization results. The mRNA is polyadenylated, since no hybridization was found on Northern blots of total RNA that was depleted of poly(A) ${ }^{+}$RNA (data not shown). This early accumulation, which starts to plateau in previtellogenic oocytes, has been found for several other poly(A) ${ }^{+}$RNAs expressed during Xenopus oogenesis (Golden et al. 1980; Jamrich et al. 1984).

The accumulation of the protein as analyzed by Western blots is delayed compared with the mRNA accumulation (Fig. 7b). There is a sharp increase in the amount of protein from stage 3 to stage 4 . Stages 2-4, especially stage 3 , are a phase of very rapid growth during oogenesis (Callen et al. 1980) and the oocytes are possibly translationally very active during these stages. Since no further increase in the amount of protein is found from stage 4 to stage 6 , it appears either that nucleoplasmin is not translated efficiently in these later stages, despite the presence of large amounts of RNA, or

ALPHA TENDENCY

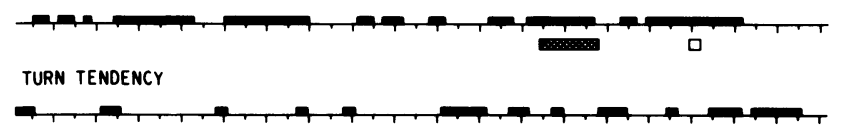

BETA TENDENCY

$\begin{array}{llllllllllllllllllllll}10 & 20 & 30 & 40 & 50 & 60 & 70 & 80 & 90 & 100 & 110 & 120 & 130 & 140 & 150 & 160 & 170 & 180 & 190\end{array}$ Figure 5. Secondary structure prediction of the amino acid sequence of N7.2. The bars indicate the regions where $\alpha$-helixes, turns, and $\beta$-sheets might form. The hatched box indicates the polyglutamic acid stretch. The open box indicates the stretch of four lysines, which is most likely involved in nuclear transport. The tail region starts upstream of the glutamic acid stretch.
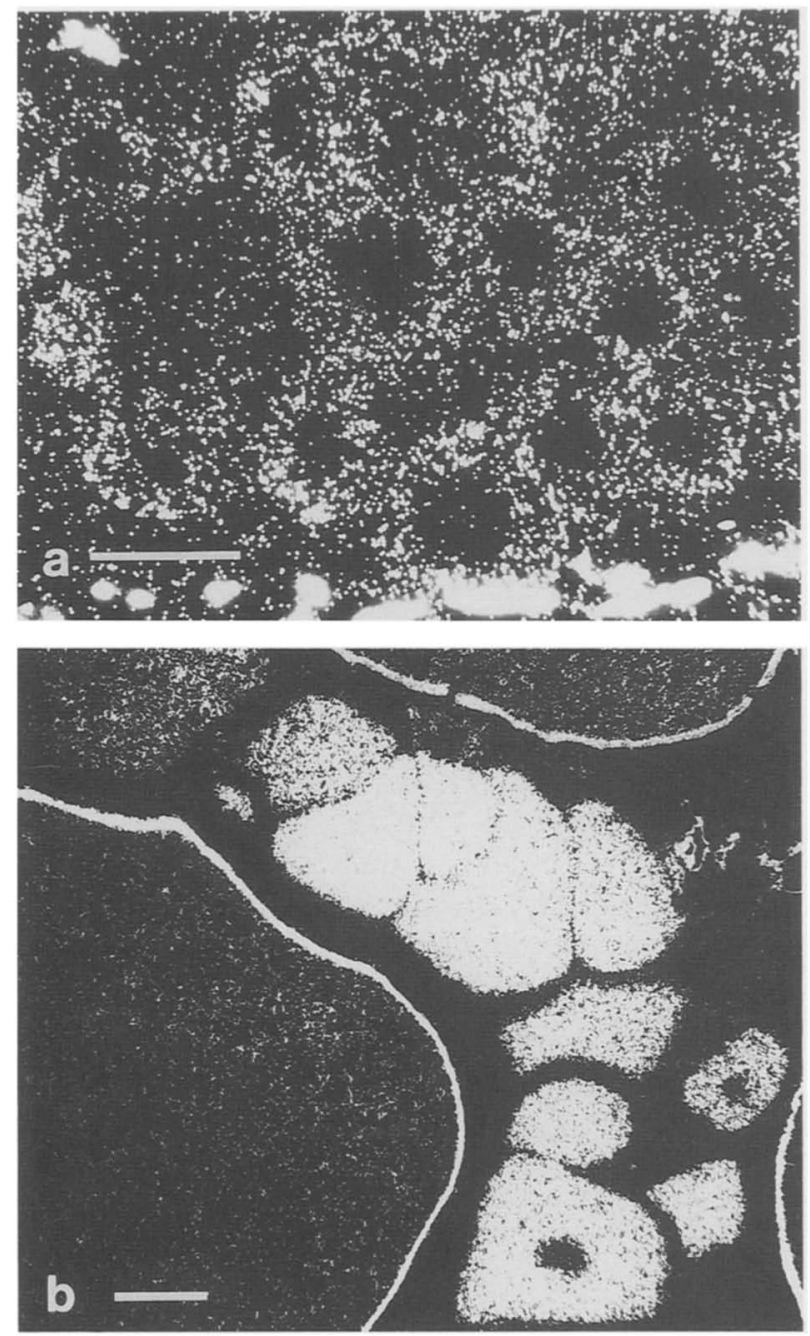

Figure 6. Dark-field micrograph of paraffin sections of oocytes hybridized with the clone N7.2 in situ. (a) Immature ovary of a young frog. Note the silver grains over the cytoplasm. Bar, 50 $\mu \mathrm{m}$. (b) Ovary of an adult frog with oocytes of different stages. Smallest oocytes are previtellogenic. Bar, $100 \mu \mathrm{m}$. This method is specific, since hybridization using U2 snRNAs was shown to be nuclear (Mattaj et al. 1985).

that new synthesis can only compensate for turnover of the protein. The latter explanation is less likely, because the protein is very stable during embryogenesis, as shown below. Nucleoplasmin is localized in the nucleus during all stages of oocyte development (Fig. 1, and data not shown).

During maturation the oocyte undergoes marked changes (for review, see Masui and Clarke 1979). Nucleoplasmin mRNA is unaffected by this maturation process, as can be seen in Figure 7a (lane M). However, nucleoplasmin protein displays a pronounced shift in electrophoretic mobility (compare lanes 6 and $M$ in Fig. 7b). Furthermore, the appearance is more heterogeneous, showing at least three bands. The change in nucleoplasmin mobility occurring during maturation is prob- 


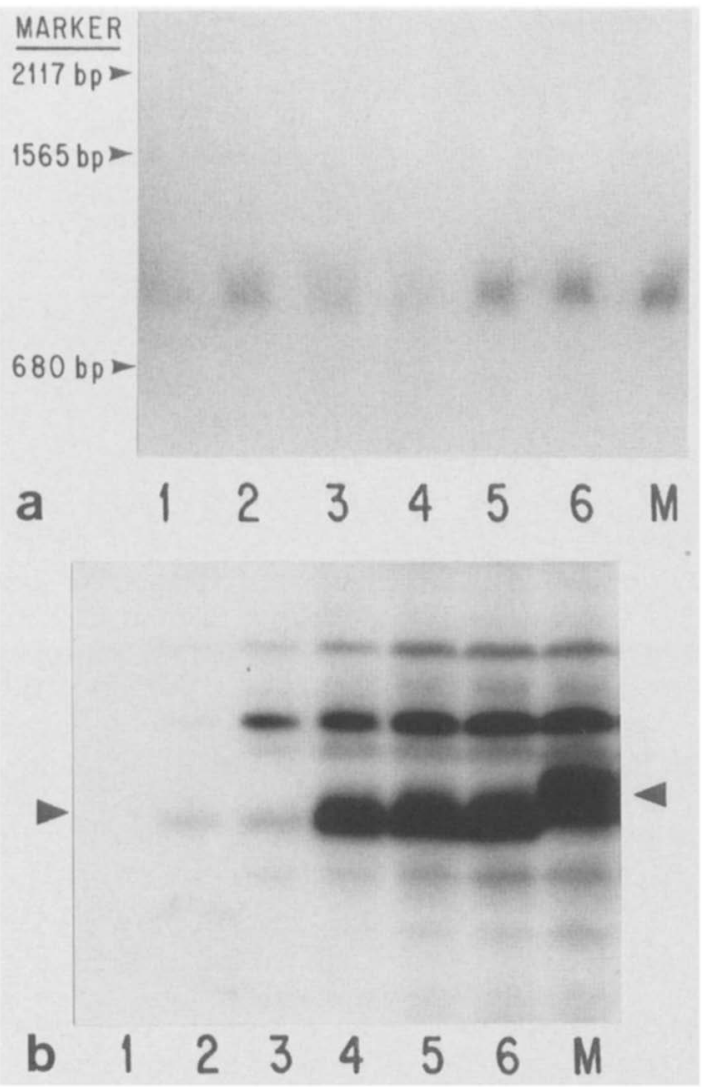

Figure 7. Developmental profile of nucleoplasmin message and protein during oogenesis. Stages of oogenesis are according to Dumont (1972). (a) Northern blot of stages $1-6$ and in vitromatured (M) oocytes probed with clone N7.2. Total RNA from 2.5 oocytes was loaded per lane. Molecular weight markers (pBR322 digested with RsaI) are indicated on the left. $(b)$ Western blot of stages 1-6, and in vitro-matured (M) oocytes. Extracts of five oocytes per lane were separated on a $15 \%$ SDS gel, transferred to nitrocellulose, and immunostained with anti-nucleoplasmin serum. Note the shift in mobility between stage 6 and matured oocytes, and that the cross-reacting bands do not shift. The gel is somewhat overexposed so as to show the fainter bands in the early stages. Arrows indicate the nucleoplasmin bands.

ably due to an increased level of phosphorylation. We have tested this by treating egg nucleoplasmin with alkaline phosphatase, which subsequently migrates on SDS gels with a similar mobility as oocyte nucleoplasmin (data not shown). Recent work by Sealy et al. (1986) and Cotten et al. (1986) has also shown, in a much more detailed way, that nucleoplasmin is indeed phosphorylated during maturation into eggs, and that the more phosphorylated form is most active in nucleosome assembly in vitro. Phosphorylation of proteins during maturation has also been observed for other proteins, e.g., ribosomal protein S6 (Maller and Sadler 1981; Martin-Pérez 1986).

\section{Nucleoplasmin during early development}

Figure 8a shows a Northern blot analysis of poly $(\mathrm{A})^{+}$ RNA from different stages of embryogenesis. Nucleoplasmin mRNA disappears rapidly during early cleavage

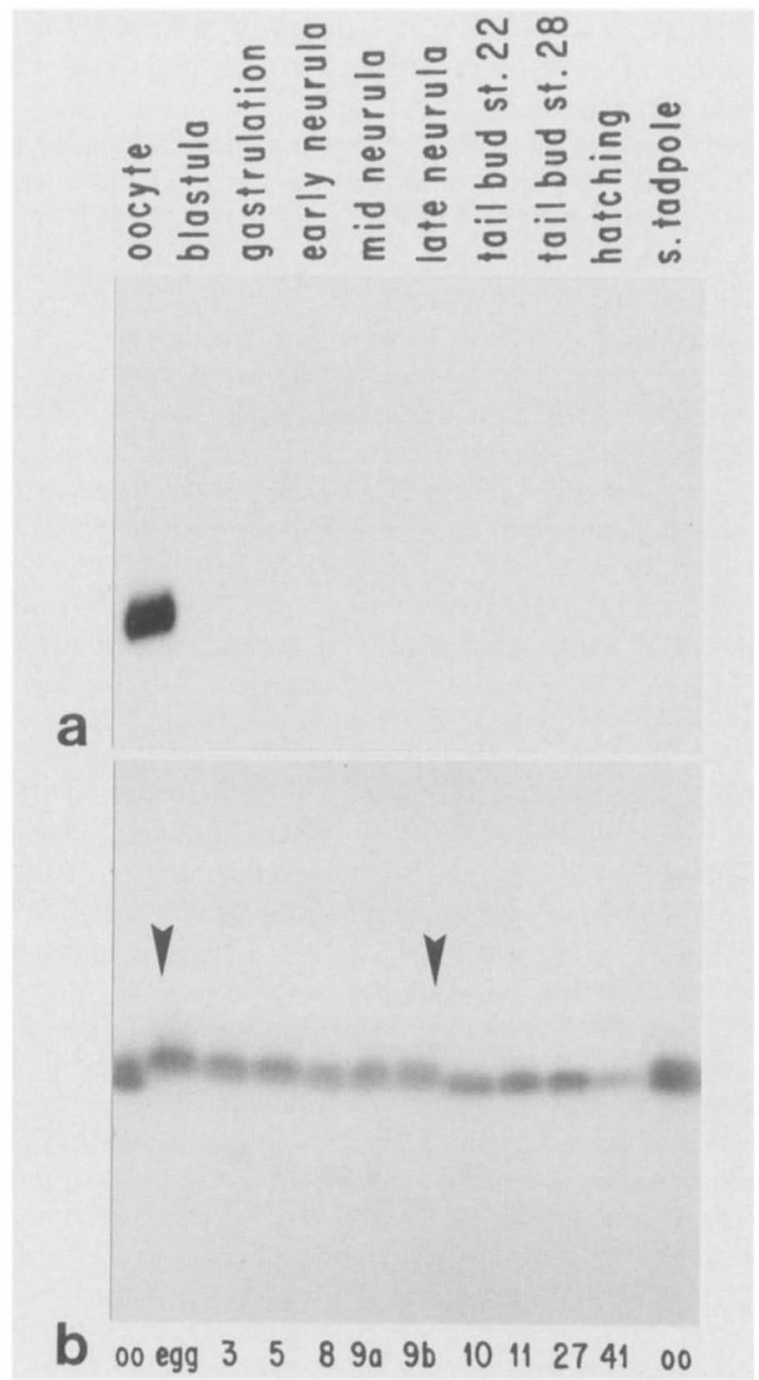

Figure 8. Developmental profile of nucleoplasmin message and protein during embryogenesis. Stages are according to Nieuwkoop and Faber (1967). (a) Northern blot of different stages of embryogenesis probed with clone N7.2. Poly(A) ${ }^{+}$RNA from 40 embryos was loaded in each lane. The same blot had previously been used by Carrasco et al. (1984) and Müller et al. (1984), showing that poly(A) ${ }^{+}$RNA is present in all stages. (b) Western blot of different stages of embryogenesis. Two stage 5 oocytes (oo), eggs, or embryos of the indicated stages were separated on a $10 \%$ SDS gel and analyzed as in Fig. $7 \mathrm{~b}$. (Lane 3) Four-cell stage; (lane 5) 16-cell stage; (lanes 8 and 9a) blastula; (lane $9 b$ ) late blastula; (lanes 10 and 11) gastrula; (lane 27) tail bud; (lane 41) swimming tadpole. Note the reduced electrophoretic mobility of nucleoplasmin protein during the period from egg to midblastula transition, when compared with oocytes and late embryos. [The impression of a gradual increase in electrophoretic mobility during early embryogenesis (egg to stage 9) is merely due to the curvature artifact ("smile" of the gel).] Arrows indicate the shifts in electrophoretic mobility. 
and cannot be detected at the level of sensitivity of our Northern blots. By densitometry of the autoradiogram of Figure 8a, we estimate that the level of nucleoplasmin mRNA in a blastula must be more than 100-fold less than in an oocyte. In an independent experiment, the difference between oocytes and embryos of stages 25 and 45 was estimated to be at least 1500-fold (data not shown). No specific hybridization was observed during the later stages of embryogenesis either, even as late as swimming tadpoles (stage 41, Fig. 8a, and data not shown for stage 45). Thus, no new stable nucleoplasmin mRNA is synthesized in tadpoles, which already contain many different types of tissues. The poly(A)- RNA fraction was also examined by Northern blots and found not to contain any nucleoplasmin mRNA in embryos (data not shown).

In contrast to the mRNA, the amount of protein stays relatively stable throughout embryogenesis as judged by Western blot analysis of embryo extracts of different stages (Fig. 8b). It starts to drop slightly only in tadpoles (stage 41 ) and hence the protein must be very stable, since there is no, or hardly any, mRNA for new synthesis. Nucleoplasmin is present in the slowly migrating (highly phosphorylated egg) form during early embryogenesis up until shortly after the midblastula transition. Between late blastula (Fig. 8b, lane 9b) and early gastrula (Fig. 8b, lane 10), nucleoplasmin is converted to a more rapidly migrating form. Apparently, nucleoplasmin seems to undergo a second change in phosphorylation that would bring the phosphorylation to a level similar to oocytes, but we have not tested this directly. During embryogenesis nucleoplasmin is nuclear (Dreyer and Hausen 1983 and our own unpublished observations). These results suggest that nucleoplasmin may not only have a function in oocytes, but probably plays an important role in nuclei during embryogenesis, especially during early cleavage, when nucleoplasmin has an increased level of phosphorylation.

\section{Discussion}

\section{Sequence of nucleoplasmin}

The deduced amino acid sequence of nucleoplasmin suggests the presence of different functional domains. The core region, which is responsible for pentamer formation (Dingwall et al. 1982), contains many hydrophobic residues. The tail region apparently contains at least two different functional parts, one potentially for nucleosome formation and one for targetting nucleoplasmin to the nucleus. The glutamic acid stretch most likely adopts a helix-turn-helix secondary structure conformation with Gly-129 in the turn. This may be the domain that is involved in nucleosome formation (Laskey et al. 1978; Earnshaw et al. 1980). The former notion is supported by the finding of Stein et al. (1979) that polyglutamic acid promotes the formation of histone into nucleosomes in the presence of DNA. Furthermore, this acidic stretch is a likely region for interactions with histones both in vivo and in vitro (Klein- schmidt et al. 1985). Rows of glutamic acids have also been found at the carboxyl terminus of homeo box-containing genes (Müller et al. 1984; Colberg-Poley et al. 1985). The homeo box is thought to be a DNA-binding domain and the polyglutamic part of the protein could interact with adjacent histones or nucleosomes. However, a databank search revealed that polyglutamic acid stretches can be found in such diverse proteins as bovine cytochrome $c 1$, ubiquinol-cytochrome $c$ reductase of yeast, sodium channel protein of electric eel, or hexon protein of adenovirus 2, indicating that polyglutamic acid may also serve other functions.

The last 50 amino acids of the tail are rather basic and, because of the high proportion of lysines and alanines, rather similar to amino acid composition of histones. Furthermore, short homologies to some histones of the H1 class can be found (Fig. 4). Since histone H1 binds to nucleosome core structure, this part of the protein may also play a role in the interactions of the nucleoplasmin pentamer with histones or nucleosomes.

Another function that resides in this part of the protein is the nuclear migration signal. We have studied this using deletion constructs of nucleoplasmin- $\beta$-galactosidase fusion proteins, and the results show that the karyophilic signal of nucleoplasmin is located in this part of the protein (Bürglin and De Robertis, in prep.).

\section{Nucleoplasmin during oogenesis}

Nucleoplasmin mRNA is expressed very early in oogenesis, distributes evenly throughout the cytoplasm, and reaches its peak concentration in stage 1 and 2 oocytes. The accumulation of the protein is not as fast but rather is concomitant with the increase in size of the oocyte, reaching a plateau at stage 4 . This poses the interesting question: What kind of translational controls first stimulate and then reduce protein synthesis from an almost constant amount of message during oogenesis?

In the oocyte, a possible function for nucleoplasmin may be to allow the accumulation of histone proteins in amounts vastly exceeding the mass of DNA (Kleinschmidt et al. 1985). Having nucleoplasmin in amounts correlated with the size of oocytes would be consistent with such a "charge compensation" function.

\section{Nucleoplasmin during embryogenesis}

Nucleoplasmin mRNA is still present in in vitro-matured oocytes, but is no longer detectable by Northern blots in blastula stages. The nucleoplasmin gene is not switched on during midblastula transition, a time at which many other genes are known to be turned on (for review, see Kirschner et al. 1985). Similarly, newly synthesized mRNA cannot be detected later, even in swimming tadpoles which contain many differentiated tissues (Fig. 8a).

During maturation, the protein undergoes a pronounced shift in electrophoretic mobility, which is the result of increased phosphorylation [our own results and 
those of Sealy et al. (1986) and Cotten et al. (1986)]. The observations presented in this paper suggest that after the midblastula transition nucleoplasmin becomes dephosphorylated to a level similar to that found in oocytes. Sealy et al. (1986) and Cotten et al. (1986) have shown that the highly phosphorylated egg nucleoplasmin is a much more efficient nucleosome assembly factor in vitro than oocyte nucleoplasmin. The high levels of nucleoplasmin phosphorylation are maintained throughout the early stages of embryogenesis which have unusually rapid cell cycles and rapid DNA replication. Such a close correlation suggests that nucleoplasmin is perhaps a nucleosome assembly factor in vivo. Later on in embryogenesis, when cell cycles are slower, the degree of phosphorylation seems to be comparable to that in oocytes and the protein continues to be present as late as swimming tadpole stages, although it is not clear whether it still is required for a specific function.

We did not investigate the expression and presence of nucleoplasmin in adult somatic tissues. In contrast to the findings of Krohne and Franke (1980a), who found the protein in nuclei from several tissues by immunolocalization using a polyclonal antiserum, an analysis of different somatic tissues with monoclonal antibodies by Dreyer and Hausen (1983) was negative. In our experiments we could not detect any mRNA in tadpoles containing highly differentiated tissues. In addition our antiserum did not stain extracts of a Xenopus kidney cell line on Western blots (unpubl.). This same cell line had been found to be positive by immunofluorescence by Krohne and Franke (1980a,b). This discrepancy will have to be resolved in order to understand whether nucleoplasmin is only required in oocytes and in early embryogenesis during the rapid cell cycles or whether it also serves a more general formation in somatic cells. Further understanding could be gained by analyzing other vertebrates for the presence of nucleoplasmin-like sequences using DNA probes so as to confirm the findings of immunologically related proteins in other species as described by Krohne and Franke (1980b).

Our results suggest that nucleoplasmin may not only be important in oogenesis but probably plays a major role during early embryogenesis, when rapid nucleosome assembly is required. With the clones and sequence available now, it should be possible to analyze further the function and role of nucleoplasmin in early development.

\section{Materials and methods}

\section{Raising of an anti-nucleoplasmin serum}

The ovaries from an adult Xenopus laevis were homogenized in $10 \mathrm{~mm}$ Tris- $\mathrm{HCl}(\mathrm{pH} 7.6), 50 \mathrm{~mm} \mathrm{NaCl}$; yolk and lipids were removed by three cycles of centrifugation at $12,000 \mathrm{~g}$ for $15 \mathrm{~min}$. The clarified extract was heat-denatured at $80^{\circ} \mathrm{C}$ for $10 \mathrm{~min}$ and centrifuged (Laskey et al. 1978), and an aliquot of the supernatant was electrophoresed in a SDS-polyacrylamide gel. The re- gion of the gel containing nucleoplasmin (essentially pure) was excised. The protein was electroeluted from the gel fragments, mixed with Freund's adjuvant, and injected into a rabbit. For later boosts, native nucleoplasmin was purified essentially as described by Dingwall et al. (1982), with modifications (Newmeyer et al. 1986).

\section{Immunolocalization of nucleoplasmin on sections of Xenopus laevis oocytes}

Paraffin sections were prepared and processed up to the application of the first antibody and the subsequent washing steps according to Zeller et al. (1983). The bound antibodies were detected using Protein A-gold complexes, as described by Lucocq and Roth (1985). Detection of the bound Protein A-gold complexes was enhanced with the photochemical silver method (Lucocq and Roth 1985). It is critical for these last steps to use dust-free solutions that have been filtered through Millipore $0.45-\mu \mathrm{m}$ nitrocellulose filters and to pre-equilibrate the sections with the reaction buffer prior to the enhancement using silver lactate.

\section{Construction of a $\lambda g t 11 \mathrm{cDNA}$ library}

Small ovaries were dissected from stage 65 froglets. Total RNA was extracted according to De Robertis et al. (1982). Poly(A) ${ }^{+}$ RNA was prepared according to Mechler and Rabbitts (1981). cDNA was prepared using a cDNA synthesis kit from New England Nuclear, and was processed according to the protocol of Huynh et al. (1984).

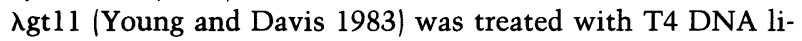
gase so as to concatemerize the DNA, digested with EcoRI to completion, and dephosphorylated with calf intestinal phosphatase (Boehringer) to such an extent that only about $0.1 \%$ of the $\lambda$ DNA could religate. cDNA was ligated into $\lambda$ gt 11 , packaged in vitro, and amplified according to Huynh et al. (1984).

\section{Screening with antibodies}

Anti-nucleoplasmin serum was depleted on anti-E. coli antibodies by passing it over $\mathrm{CNBr}$-Sepharose (Pharmacia) columns that had been coupled with E. coli Y1090 extracts (Young and Davis 1985).

About 50,000 plaques per Petri dish (14-cm diameter) were plated on L-agar. After $5 \mathrm{hr}$ at $42^{\circ} \mathrm{C}$, nitrocellulose filters (Schleicher and Schuell) that had been soaked previously with $10 \mathrm{mM}$ IPTG (Sigma) and air-dried were placed on the plates, and the incubation was continued at $37^{\circ} \mathrm{C}$ for another $2 \mathrm{hr}$. Filters were then removed and processed according to the Western blot immunostaining protocol described by Fritz et al. (1984). During the rescreening the color indicator X-Gal (Sigma) was included in the phage platings, because the blue color produced by the few wild-type $\lambda$ gt 11 phages present in the library transferred to the nitrocellulose from the plates and thus allowed optimal alignments. For the last rescreen usually two plates were prepared. One plate contained only the almost pure phage and was plated at low dilution, and in the second plate the same amount of positive phage was mixed with a stock of wild-type $\lambda$ gtll so as to produce a homogeneous background. This was especially helpful when sera were reused several times and when the positive signal was weak. The wild-type background would provide an internal reference to which the positives could be compared and their number determined. Phage DNA and bacterial extracts containing fusion proteins were prepared according to Huynh et al. (1984) and Young and Davis (1985). 


\section{Protein gels and Western blots}

Protein extracts from two to five oocytes or embryos were homogenized in $50 \mu \mathrm{l}$ as described for the antiserum preparation, except that only one centrifugation in a tabletop centrifuge at $1000 \mathrm{~g}$ was performed to remove yolk and lipids. Protein molecular weight markers were obtained from Bio-Rad Laboratories. SDS-polyacrylamide gel electrophoresis was performed according to Takacs (1979); $7.5 \%$ gels were used for $\beta$-galactosidase fusion proteins and $10 \%$ or $15 \%$ gels were used for nucleoplasmin blots. Transfer of proteins to nitrocellulose (Western blots) was performed according to Towbin et al. (1979). For immunostaining of the blots the protocol of Fritz et al. (1984) was used.

\section{Elution of antibodies from nitrocellulose}

A modified version of the protocol by Olmsted (1981) was used. A strip containing the appropriate protein was cut from the nitrocellulose blot and washed with TBS (Fritz et al. 1984) for 10 $\mathrm{min}$. The strip was subsequently incubated in $3 \mathrm{M}$ urea, $100 \mathrm{mM}$ $\mathrm{MgCl}_{2}$ for $10 \mathrm{~min}$ and then saturated with solution A (Zeller et al. 1983) for about $30 \mathrm{~min}$. It was then incubated with an excess of serum (1:5 or 1:10 dilution) for $1-2 \mathrm{hr}$, and washed twice with solution $\mathrm{A}$ for $10 \mathrm{~min}$. The affinity-purified antibodies were eluted by washing the strip three times with $0.5 \mathrm{ml}$ of 0.15 M glycine ( $\mathrm{pH} 2.0)$ for $1 \mathrm{~min}$. The three eluates were immediately combined in a tube containing $1 / 10$ volume $2 \mathrm{M}$ Tris $-\mathrm{HCl}$ (pH 8.0) and then dialyzed against TBS for $2 \mathrm{hr}$ at $4^{\circ} \mathrm{C}$. One volume of solution A was added and the mix was stored at $-20^{\circ} \mathrm{C}$. This solution was applied undiluted to strips as affinity-purified antibodies.

\section{Subcloning and sequencing}

For restriction maps and subcloning into pAT 153 (Twigg and Sherratt 1980) standard agarose gel, restriction digest, and ligation methods were used (Maniatis et al. 1982). The cDNA was subcloned in both orientations into M13 mp8 (Messing and Vieira 1982) and both strands were sequenced using the dideoxy method of Sanger et al. (1977). Restriction sites in the clone were used for subcloning and sequencing of smaller fragments.

For secondary structure analysis a program by James $D$. Conway, using the parameters of Chou and Fasman (1978), was employed. For the homology searches the protein sequence database of the protein identification resource of the National Biomedical Foundation was used.

\section{In situ hybridization to oocyte and embryo sections}

Oocytes and embryos were embedded and sectioned as described by Zeller et al. (1983). Sections were mounted on glass slides coated with 3-aminopropyltriethoxysilane (Fluka AF, CH-9470 Buchs) according to Gottlieb and Glaser (1975), and prepared for hybridization according to Hafen et al. (1983). Pronase digestion (from 0.15 to $0.35 \mathrm{mg} / \mathrm{ml}$ final concentration) was controlled with acridine orange staining for maximal RNA retention (Hafen et al. 1983). The slides were then acetylated as follows (Hayashi et al. 1978): $500 \mu \mathrm{l}$ acetic anhydride was mixed rapidly with $200 \mathrm{ml}$ of $0.1 \mathrm{M}$ triethanolamine- $\mathrm{HCl} / \mathrm{pH}$ 8.0) (the half-life of acetic anhydride in this buffer is $1 \mathrm{~min}$ ) and the slides were incubated twice in this solution for $5 \mathrm{~min}$. The slides were then washed for $5 \mathrm{~min}$ in $2 \times \mathrm{SSC}$ at $20^{\circ} \mathrm{C}$, dehydrated using graded ethanols, and left to air dry. Hybridization using the ${ }^{3} \mathrm{H}$-nick-translated $\mathrm{cDNA}$ as a probe and exposure to emulsion was carried out as by Hafen et al. (1983).

\section{Staging of oocytes and embryos}

Oocytes were manually separated into the six stages of oogenesis (Dumont 1972). In vitro-matured oocytes were obtained by incubating dissected ovaries in 50 units $/ \mathrm{ml}$ of Pregnyl from Organon (human chorionic gonadotropin) in modified Barth's saline (Gurdon 1976) at $19^{\circ} \mathrm{C}$ overnight. The matured oocytes were identified by the white spot resulting from germinal vesicle breakdown. Staging of embryos was according to Nieuwkoop and Faber (1967).

\section{Northern blots}

For the oocyte Northern blot, total RNA of the different stages was prepared according to De Robertis et al. (1982) and 2.5 oocyte equivalents of each stage were run on a formaldehydeagarose gel as described in Maniatis et al. (1982). ${ }^{32} \mathrm{P}$-nick-translation and hybridization at high stringency were carried out as in Maniatis et al. (1982). For the embryo Northern blot, the same nitrocellulose filter prepared by Carrasco et al. (1984) was used. Autoradiographs were scanned using a Bio-Rad Laboratories Model 620 video densitometer to determine ratios between bands.

\section{Acknowledgments}

We are indebted to a number of colleagues for much help and advice during this project. We would like to thank Ken Cho and George Martin for help with the Northern blots, Jane Wright for helping with the in situ hybridizations, Peter Nielsen for advice on the $\lambda$ gtll screening, Jürgen Roth for providing us with Protein A-gold, Kitaru Suda for providing ${ }^{131}$ I-Protein A, Bruce Blumberg for his advice during the computer searches, and James D. Conway for providing the secondary structure program. We specially thank Larry Tabata for his fine graphic work, and Christopher Wright and Ken Cho for advice on the manuscript. This work was supported by grants of the Swiss National Science Fund, the Kanton Basel-Stadt, the Weingart Foundation, the W.M. Keck Foundation, and the National Institutes of Health.

\section{Note}

Sequence data described in this paper have been submitted to the EMBL/GenBank Data Libraries under the accession number Y00204.

\section{Note added in proof}

The work on cloning of the variant nucleoplasmin is now in press (C. Dingwall, S.M. Dilworth, S.J. Black, S.E. Kearsey, L.S. Cox, and R.A. Laskey. 1987. EMBO I.)

\section{References}

Callen, J.C., N. Dennebouy, and J.C. Mounolou. 1980. Kinetic analysis of entire oogenesis in Xenopus laevis. Dev. Growth Differ. 22: 831-840.

Carrasco, A.E., W. McGinnis, W.J. Gehring, and E.M. De Robertis. 1984. Cloning of an X. laevis gene expressed during early embryogenesis coding for a peptide region homologous to Drosophila homeotic genes. Cell 37: 409-414.

Chou, P.Y. and G.D. Fasman. 1978. Empirical predictions of protein conformation. Annu. Rev. Biochem. 47: 251-276. 
Colberg-Poley, A.M., S.D. Voss, K. Chowdhury, and P. Gruss. 1985. Structural analysis of murine genes containing homeo box sequences and their expression in embryonal carcinoma cells. Nature 314: 713-718.

Cotten, M., L. Sealy, and R. Chalkley. 1986. Massive phosphorylation distinguishes Xenopus laevis nucleoplasmin isolated from oocytes or unfertilized eggs. Biochemistry 25: 5063-5069.

De Robertis, E.M., S. Lienhard, and R.F. Parisot. 1982. Intracellular transport of microinjected $5 \mathrm{~S}$ and small nuclear RNAs. Nature 295: 572-577.

Dingwall, C. and J. Allan. 1984. Accumulation of the isolated carboxy-terminal domain of histone $\mathrm{H} 1$ in the Xenopus oocyte nucleus. EMBO I. 3: 1933-1937.

Dingwall, C., S.V. Sharnick, and R.A. Laskey. 1982. A polypeptide domain that specifies migration of nucleoplasmin into the nucleus. Cell 30: 449-458.

Dingwall, C., T.R. Bürglin, S.E. Kearsey, S. Dilworth, and R.A. Laskey. 1986. Sequence features of the nucleoplasmin tail region and evidence for a selective entry mechanism for transport into the cell nucleus. In Nucleocytoplasmic transport (ed. R. Peters and H.F. Trendelenburg), pp. 159-169. Springer-Verlag, Berlin, Heidelberg.

Dreyer, C. and P. Hausen. 1983. Two-dimensional gel analysis of the fate of oocyte nuclear proteins in the development of Xenopus laevis. Dev. Biol. 100: 412-425.

Dumont, J.N. 1972. Oogenesis in Xenopus laevis (Daudin). 1. Stages of oocyte development in laboratory maintained animals. J. Morphol. 136: 153-180.

Earnshaw, W.C., B.W. Honda, and R.A. Laskey. 1980. Assembly of nucleosomes: the reaction involving $X$. laevis nucleoplasmin. Cell 21: 373-383.

Feldherr, C.M., E. Kallenbach, and N. Schultz. 1984. Movement of a karyophilic protein through the nuclear pores of oocytes. J. Cell Biol. 99: 2216-2222.

Fritz, A., R. Parisot, D. Newmeyer, and E.M. De Robertis. 1984. Small nuclear U-ribonucleoproteins in Xenopus laevis development. J. Mol. Biol. 178: 273-285.

Golden, L., U. Schafer, and M. Rosbash. 1980. Accumulation of individual $\mathrm{pA}^{+} \mathrm{RNAs}$ during oogenesis of Xenopus laevis. Cell 22: 835-844.

Gottlieb, D.J. and L. Glaser. 1975. A novel assay of neuronal cell adhesion. Biochem. Biophys. Res. Commun. 63: 815821.

Gurdon, J.B. 1976. Injected nuclei in frog oocytes: Fate, enlargement, and chromatin dispersal. J. Embryol. Exp. Morphol. 36: $523-540$.

Hafen, E., M. Levine, R.L. Garber, and W.J. Gehring. 1983. An improved in situ hybridization method for the detection of cellular RNAs in Drosophila tissue sections and its application for localizing transcripts of the homeotic Antennapedia gene complex. EMBO I. 2: 617-623.

Hausen, P., Y.H. Wang, C. Dreyer, and R. Stick. 1985. Distribution of nuclear proteins during maturation of the Xenopus oocyte. J. Embryol. Exp. Morphol. (suppl.) 89: 17-34.

Hayashi, S., I.C. Gillam, A.D. Delaney, and G.M. Tener. 1978. Acetylation of chromosome squashes of Drosophila melanogaster decreases the background in autoradiographs from hybridization with [125I]-labeled RNA. I. Histochem. Cytochem. 26: 677-679.

Huynh, T.V., R.A. Young, and R.W. Davis. 1984. Constructing and screening cDNA libraries in $\lambda$ gt10 and $\lambda g t 11$. In DNA cloning techniques: A practical approach (ed. D. Glover), pp. 49-78. IRL Press, Oxford.

Jamrich, M., K.A. Mahon, E.R. Gavis, and J.G. Gall. 1984. Histone RNA in amphibian oocytes visualized by in situ hy- bridisation to methacrylate-embedded tissue sections. $E M B O$ I. 3: 1939-1943.

Kirschner, M., J. Newport, and J. Gerhart. 1985. The timing of early developmental events in Xenopus. Trends Genet. 1: $41-47$.

Kleinschmidt, J.A., E. Fortkamp, G. Krohne, H. Zentgraf, and W.W. Franke. 1985. Co-existence of two different types of soluble histone complexes in nuclei of Xenopus laevis oocytes. I. Biol. Chem. 260: 1166-1176.

Krohne, G. and W.W. Franke. 1980a. Immunological identification and localization of the predominant nuclear protein of the amphibian oocyte nucleus. Proc. Natl. Acad. Sci. 77: $1034-1038$.

-1980b. A major soluble acidic protein located in nuclei of diverse vertebrate species. Exp. Cell Res. 129: 167-189.

Laskey, R.A., B.M. Honda, A.D. Mills, and J.T. Finch. 1978. Nucleosomes are assembled by an acidic protein which binds histones and transfers them to DNA. Nature 275: 416-420.

Lucocq, J.M. and J. Roth. 1985. Colloidal gold and colloidal silver-metallic markers for light microscopical histochemistry. In Techniques in immunocytochemistry (ed. G.R. Bullock and P. Petrusz), vol. III. Academic Press, London.

Maller, J.L. and S.E. Sadler. 1981. Regulation of steroid-induced cell division in amphibian oocytes by protein phosphorylation. Cold Spring Harbor Conf. Cell Prolif. 8: 1127-1141.

Maniatis, T., E.F. Fritsch, and J. Sambrook. 1982. Molecular cloning: A laboratory manual. Cold Spring Harbor Laboratory, Cold Spring Harbor, New York.

Martin-Pérez, J., B.B. Rudkin, M. Siegmann, and G. Thomas. 1986. Activation of ribosomal protein S6 phosphorylation during meiotic maturation of Xenopus laevis oocytes: In vitro ordered appearance of S6 phosphopeptides. EMBO I. 5: 725-731.

Masui, Y. and H.J. Clarke. 1979. Oocyte maturation. Int. Rev. Cytol. 57: 185-282.

Mattaj, I.W., R. Zeller, A.E. Carrasco, M. Jamrich, S. Lienhard, and E.M. De Robertis. 1985. U snRNA gene families in Xenopus laevis. In Oxford surveys on eukaryotic genes (ed. N. Maclean), vol. 2, pp. 121-140. Oxford University Press, Oxford.

Mechler, B. and T.H. Rabbitts. 1981. Membrane-bound ribosomes of myeloma cells. IV. mRNA complexity of free and membrane-bound polysomes. J. Cell Biol. 88: 29-36.

Messing, J. and J. Vieira. 1982. A new pair of M13 vectors for selecting either DNA strand of double-digest restriction fragments. Gene 19: 269-276.

Mills, A.D., R.A. Laskey, P. Black, and E.M. De Robertis. 1980. An acidic protein which assembles nucleosomes in vitro is the most abundant protein in Xenopus oocyte nuclei. J. Mol. Biol. 139: 561-568.

Müller, M.M., A.E. Carrasco, and E.M. De Robertis. 1984. A homeo-box-containing gene expressed during oogenesis in Xenopus. Cell 39: 157-162.

Newmeyer, D.D., J.M. Lucocq, T.R. Bürglin, and E.M. De Robertis. 1986. Assembly in vitro of nuclei active in nuclear protein transport: ATP is required for nucleoplasmin accumulation. $E M B O$ J. 5: 501-510.

Nieuwkoop, P.D. and J. Faber. 1967. Normal table of Xenopus laevis (Daudin), 2nd ed. North Holland, Amsterdam.

Olmsted, J.B. 1981. Affinity purification of antibodies from diazotized paper blots of heterogeneous protein samples. $J$. Biol. Chem. 256: 11955-11957.

Sanger, F., S. Nicklen, and A.R. Coulson. 1977. DNA sequencing with chain-terminating inhibitors. Proc. Natl. Acad. Sci. 74: 5463-5467. 
Sealy, L., M. Cotten, and R. Chalkley. 1986. Xenopus nucleoplasmin: Egg vs. oocyte. Biochemistry 25: 3064-3072.

Stein, A., J.P. Whitlock, Jr., and M. Bina. 1979. Acidic polypeptides can assemble both histones and chromatin in vitro at physiological ionic strength. Proc. Natl. Acad. Sci. 76: 5000-5004.

Takacs, B.J. 1979. Electrophoresis of proteins in polyacrylamide slab gels. In Immunological methods (ed. I. Lefkovits and B. Pernis), pp. 81-105. Academic Press, New York.

Tang, J. 1963. Specificity of pepsin and its dependence on a possible hydrophobic binding site. Nature 199: 1094-1095.

Towbin, H., T. Staehelin, and J. Gordon. 1979. Electrophoretic transfer of proteins from polyacrylamide gels to nitrocellulose sheets: Procedure and some applications. Proc. Natl. Acad. Sci. 76: 4350-4354.

Twigg, A.J. and D. Sherratt. 1980. Trans-complementable copynumber mutants of plasmid ColE1. Nature 283: 216-218.

Young, R.A. and R.W. Davis. 1983. Efficient isolation of genes by using antibody probes. Proc. Natl. Acad. Sci. 80: 11941198.

1985. Immunoscreening $\lambda$ gt 11 recombinant DNA expression libraries. In Genetic engineering: Principles and methods (ed. J.K. Setlow and A. Hollaender), pp. 29-42. Plenum Press, New York and London.

Zeller, R., T. Nyffenegger, and E.M. De Robertis. 1983. Nucleocytoplasmic distribution of snRNPs and stockpiled snRNABinding proteins during oogenesis and early development in Xenopus laevis. Cell 32: 425-434. 


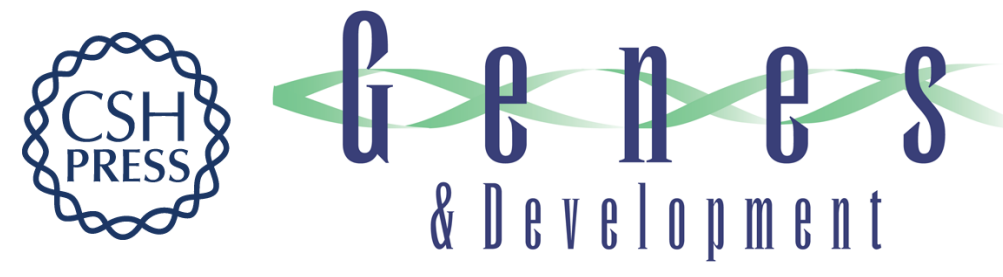

\section{Cloning of nucleoplasmin from Xenopus laevis oocytes and analysis of its developmental expression.}

T R Bürglin, I W Mattaj, D D Newmeyer, et al.

Genes Dev. 1987, 1:

Access the most recent version at doi:10.1101/gad.1.1.97

References This article cites 42 articles, 9 of which can be accessed free at: http://genesdev.cshlp.org/content/1/1/97.full.html\#ref-list-1

License

Email Alerting

Receive free email alerts when new articles cite this article - sign up in the box at the top Service right corner of the article or click here.

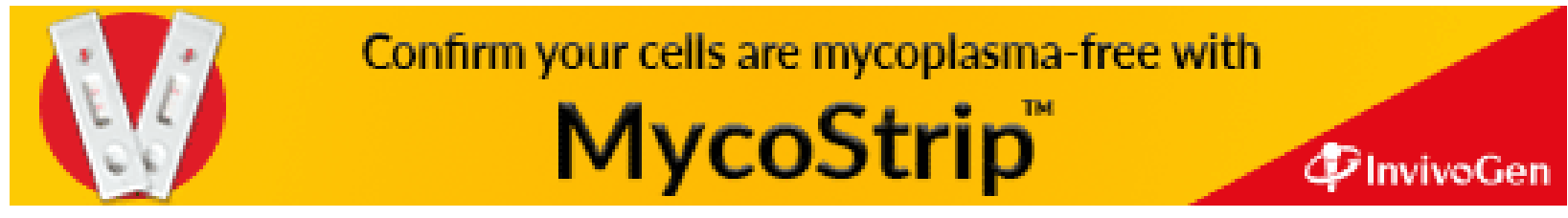

